\title{
Siderophore production by Aeromonas salmonicida subsp. salmonicida. Lack of strain specificity
}

\author{
A. I. G. Fernandez ${ }^{1}$, A. F. Fernández ${ }^{1}$, M. J. Pérez ${ }^{1}$, T. P. Nieto ${ }^{1 *}$, A. E. Ellis ${ }^{2}$ \\ ${ }^{1}$ Dpto Biología Funcional y Ciencias de la Salud, Facultad de Ciencias, Universidad de Vigo, Lagoas-Marcosende, \\ E-36200 Vigo, Spain \\ ${ }^{2}$ FRS Marine Laboratory, PO Box 101, Victoria Road, Aberdeen AB 11 9DB, Scotland, UK
}

\begin{abstract}
Siderophore production, presence of iron-regulated outer membrane proteins and siderophore specificity was determined among 17 jsolates of Aeromonas salmonicida subsp. salmonicida obtained from Spain and Scotland. All grew in the presence of ethylenediamine di(o-hydroxyphenylacetic acid) (EDDA) and siderophore production was detected using chrome azurol S (CAS) agar, confurming the presence of a high-affinity suderophore iron-uptake mechanism. The Arnow test confirmed that all isolates produced a catechol siderophore. Cross-feeding assays with indicator bacterla showed the absence of anguibactin, enterobactin, 2,3-dihydroxybenzoic acid (DHBA) and the hydroxamate siderophore, aerobactin, in the iron-restricted supernants of a representative isolate which cross fed 15/17 A. salmonicida isolates tested. Sodium dodecyl sulphate polyacrylamide gel electrophoresis (SDS-PAGE) showed the presence of the same 2 major iron-regulated outer membrane proteins (IROMPs) in all isolates when grown in iron-restricted conditions and siderophore strain specificity as assessed by cross-feeding experiments was not apparent. Thus, with respect to IROMP and siderophore production $A$. salmonicida appears to be a homogeneous species.
\end{abstract}

KEY WORDS: Aeromonas salmonicida subsp. salmonicida S Siderophore · Cross-feeding assay

\section{INTRODUCTION}

Aeromonas salmonicida subsp. salmonicida is the causative agent of furunculosis in salmonid fish and produces a systemic disease which results in a chronic or acute haemorrhagic septicaemia, often with extensive liquefaction of host tissues (Munro \& Hastings 1993).

Aeromonas salmonicida has the ability to grow rapidly in fish and produce disease. The bacterium is known to produce a siderophore-mediated iron uptake system (Chart \& Trust 1983, Hirst et al. 1991), which may be one of the ways the bacterium obtains iron for growth in vivo from the host iron-binding proteins. In many pathogenic bacteria this mechanism consists of 2 elements, the ferric chelating siderophore itself and a cell-associated receptor that processes the ferrisiderophore for delivering the metal to the cytoplasm. The

\footnotetext{
·Addressee for correspondence. E-mail: mtperez@uvigo.es
}

cell-associated receptor is specific for its homologous siderophore and is responsible for siderophore strain specificity. In $A$ salmonicida the siderophore has been characterised as a catechol-phenolate but, using 4 strains of $A$. salmonicida, a limited ability of siderophore-containing supernatants to cross-feed other strains was reported to suggest a siderophore strain specificity (Hirst et al. 1991). When grown under ironrestricted conditions, the bacterium expressed ironregulated outer membrane proteins with molecular weight (MW) ranging from 74 to $86 \mathrm{kDa}$ (Neelam et al. 1993, Hirst \& Ellis 1994). The genes coding for these proteins have been sequenced (Collighan et al. 1998) and are homologous with siderophore binding-proteins characterised from Escherichia coli and Vibrio anguillarum. While studies (Chart \& Trust 1983, Hirst et al. 1991) demonstrated siderophore production in typical strains of $A$. salmonicida, the exact nature of this siderophore is still controversial and the question of strain specificity, suggested by Hirst et al., requires further investigation. The aim of the present study, 
using 17 isolates from Spain and Scotland, was to determine if siderophore production is widely distributed among isolates of $A$. salmonicida subsp. salmonicida, to investigate the presence and variability of ironregulated outer membrane proteins and to clarify if there is substantive evidence for siderophore strain specificity.

\section{MATERIAL AND METHODS}

Bacteria. Seventeen Aeromonas salmonicida subsp. salmonicida isolates were used in this study (Table 1). Eight were isolated in the northwest of Spain and 9 from different parts of Scotland. Bacteria were routinely grown either in tryptone soy broth (TSB, Oxoid) or on tryptone soy agar (TSA, Oxoid) at $22^{\circ} \mathrm{C}$ for $72 \mathrm{~h}$, and were stored frozen at $-70^{\circ} \mathrm{C}$ in TSB with $15 \%$ (v/v) glycerol. Ethylenediamine di(o-hydroxy-phenylacetic acid) (EDDA, Sigma) was added to $10 \mu \mathrm{M}$ to induce conditions of iron restriction. Contaminating iron was removed from EDDA by the method of Rogers (1973). Bacteria were subcultured 3 times on the ironrestricted media before use to reduce internal ferric iron stores. All glassware was washed in $6 \mathrm{M} \mathrm{HCl}$ and rinsed 10 times in deionized-distilled water obtained from a Milli-Q water purification system (Millipore).

Growth under iron-restricted conditions. The ability of Aeromonas salmonicida isolates to grow in the presence of EDDA was determined on TSA. The minimal inhibitory concentration of EDDA was obtained as follows. Exponcntial cultures obtained by growing single colonies in TSB were spread on TSA plates supplemented with increasing concentrations of EDDA. Growth was scored after $72 \mathrm{~h}$. The lowest EDDA concentration at which no growth was detected was recorded as the minimal inhibitory concentration (MIC) of EDDA

Production of siderophores. Bacteria were screened for the production of siderophores by the method of Schwyn \& Neilands (1987) using chrome azurol S (CAS) agar. Briefly, the assay was performed by spotting $10 \mu \mathrm{l}$ of each exponential bacterial culture previously grown under iron-restricted conditions in TSB onto CAS agar. The siderophore levels produced by the isolates were recorded as the diameter of the orange halo produced by the colony.

The presence of catechol and/or hydroxamate siderophores in unconcentrated culture supernatants obtained from bacteria grown either in normal or ironrestricted conditions in TSB was quantitatively determined by the colorimetric assay of Arnow (1937), using 2,3-dihydroxybenzoic acid (DHBA, Sigma) and the Atkin et al. (1970) method, using desferrioxamine mesylate (Desferal, Ciba-Geigy) as standards respectively.

Cross-feeding assays. Cross-feeding assays were carried out as previously described (Hirst et al. 1991) on TSA plates containing a concentration of EDDA

Table 1. Aeromonas salmonicida. Siderophore production by isolates. MIC: minimal inhibitory concentration; EDDA: ethylenediamine di(o-hydroxy-phenylacetic acid)

\begin{tabular}{|c|c|c|c|c|c|}
\hline \multirow{3}{*}{$\begin{array}{l}\text { Strain } \\
\text { MT } 984^{\text {a.1 }}\end{array}$} & \multirow{3}{*}{$\begin{array}{l}\text { MIC ( } \mu M) \text { of } \\
\text { EDDA } \\
558\end{array}$} & \multicolumn{2}{|c|}{$\begin{array}{l}\text { Concentration phenolate } \\
\text { siderophore }(\mu \mathrm{M}) \text { in }\end{array}$} & \multicolumn{2}{|c|}{$\begin{array}{c}\text { Concentration hydroxamate } \\
\text { siderophore }(\mu \mathrm{M}) \text { in }\end{array}$} \\
\hline & & \multicolumn{2}{|c|}{$\begin{array}{c}\text { iron normal iron-restricted } \\
\text { supernatants }\end{array}$} & \multicolumn{2}{|c|}{$\begin{array}{c}\text { iron normal iron-restricted } \\
\text { supernatants }\end{array}$} \\
\hline & & 63 & 149 & 87 & 78 \\
\hline MT $1001^{a, 1}$ & 1117 & 44 & 105 & 45 & 39 \\
\hline MT $1007^{a, 1}$ & 558 & 24 & 163 & NT & NT \\
\hline MT $975^{a .1}$ & 838 & 54 & 63 & 59 & 53 \\
\hline MT $1025^{\mathrm{d}, 1}$ & 1300 & 150 & 80 & 64 & 40 \\
\hline MT $973^{4.1}$ & 558 & 34 & 83 & 67 & 39 \\
\hline MT $961^{a, 1}$ & 1117 & 15 & 136 & 85 & 64 \\
\hline MT 1027 & 1117 & 76 & 90 & 65 & 46 \\
\hline MT $1038^{0,1}$ & 1117 & 65 & 87 & NT & NT \\
\hline TO.11.1 $1^{\mathrm{b} .2}$ & 558 & 28 & 87 & 86 & 58 \\
\hline$P P-42^{b, 2}$ & 558 & 206 & 193 & 98 & 107 \\
\hline $\mathrm{Al}_{103 \mathrm{~B}^{\mathrm{C}, 3}}$ & 558 & 11 & 86 & 24 & 34 \\
\hline $\operatorname{SCO} 4,1^{\mathrm{d}, 2}$ & 1117 & 10 & 78 & 107 & 82 \\
\hline $\mathrm{Al}_{127 \mathrm{~B}}$ & 558 & 18 & 44 & 33 & 0 \\
\hline$N F-21.3^{0.2}$ & 1117 & 100 & 99 & 31 & 30 \\
\hline$N F-19.1^{c .2}$ & 111.7 & 113 & 98 & NT & NT \\
\hline PP- $91^{\text {b. } 2}$ & 558 & 126 & 102 & NT & NT \\
\hline
\end{tabular}


higher than the MIC of EDDA for each isolate. The plates were seeded with approximately $10^{5}$ colonyforming units Aeromonas salmonicida. The diameter of a growth halo around a $3 \mathrm{~mm}$ diameter well containing $30 \mu$ of culture supernatant was measured after incubation for $48 \mathrm{~h}$ at $22^{\circ} \mathrm{C}$. The value was corrected by subtraction of the well diameter. The samples included culture supernatants of $A$. salmonicida obtained from cultures grown in TSB for $48 \mathrm{~h}$ at $22^{\circ} \mathrm{C}$ either in nonrestricted or in iron-restricted conditions. Growth stimulation was recorded as positive if the diameter of the halo was greater than $4 \mathrm{~mm}$. TSB and TSB with EDDA were added to wells as negative controls.

Production of the catechol-type siderophores enterobactin and anguibactin and the hydroxamate-type siderophore, aerobactin, was determined by bioassays as previously described using iron-restricted supernatant of Aeromonas salmonicida strain TO.11.1. Vibrio anguillarum 775::Tn/-5 was used as indicator for anguibactin (Crosa et al. 1983). Escherichia coli LG1522 was used as indicator strain to detect aerobactin production (Williams 1979). Salmonella typhimurium mutants enb-1 and enb-7 were used as indicator strains to detect the production of enterobactin and DHBA (Pollack et al. 1970). These indicator strains were kindly donated by Dr A. E. Toranzo, University of Santiago de Compostela, Spain.

Iron-regulated outer membrane proteins (IROMPs). Induction of IROMPs were examined by growing the bacteria in CM9 minimal medium [prepared as described by Schwyn \& Neilands (1987)] in the presence of $10 \mu \mathrm{M}$ EDDA and comparing the protein patterns with those obtained when bacteria were grown in CM9 medium supplemented with $10 \mu \mathrm{M} \mathrm{FeCl}$.

Total membrane proteins were prepared as described by Aznar et al. (1989), and the outer membrane fractions were obtained by the method of Filip et al. (1973) by differential solubilization of the bacterial cell envelopes using $1.5 \%$ sodium lauryl sarcosinate (Sarcosyl, Sigma). Pellets from total and outer membrane fractions were suspended in sample buffer, applied and run in a sodium dodecyl sulfate $12.5 \%$ polyacrylamide gel (SDS-PAGE) as described by Laemmli $(1970)$. The seperated proteins were visualized by silver staining (Morrisey 1981).

\section{RESULTS}

\section{Growth of Aeromonas salmonicida under conditions of iron restriction}

All the isolates grew under iron-restricted conditions. The growth on media supplemented with $10 \mu \mathrm{M}$ EDDA was similar to that observed on TSA alone.
The MIC for the isolates ranged from 558 to $1300 \mu \mathrm{M}$ EDDA (Table 1). This feature formed the basis of the cross-feeding assays in which culture supernatants of the various isolates of Aeromonas salmonicida were evaluated for their ability to reverse the growth restriction imposed by the MIC of EDDA for a particular isolate.

\section{Production of siderophore}

Siderophore production by all isolates was detected on CAS agar. Important quantities of a phenolate siderophore were detected by the method of Arnow (1937) in non-iron-restricted culture supernatants of all isolates. Production of this catechol siderophore was enhanced in iron-restricted culture supernatants of $12 / 17$ isolates as shown in Table 1 . The colorimetric assay of Atkin et al. (1970) for the detection of hydroxamate siderophores was positive for both ironrestricted and non-iron-restricted culture supernatants, but the concentration of this compound decreased in the iron-restricted culture supernatants of $11 / 13$ tested isolates (Table 1).

\section{Cross-feeding assays}

The ability of the siderophore(s) present in the ironrestricted culture supernatants of each of the 17 isolates to cross-feed the other isolates was examined using a siderophore bioassay. Results are presented in Table 2. As controls, untreated as well as ironrestricted medium failed to support the growth of any isolate. Growth of 1 isolate (MT 1038) was stimulated by all supernatants. Growth of 5 isolates (MT 1001, MT 1025, SCO 4.1, NF-19.1, PP-91) was stimulated by 33/34 iron and non-iron-restricted culture supernatants, the only exception being the supernatants of isolate $\mathrm{AI}_{127 \mathrm{~B}}$ obtained in iron-restricted conditions. Growth of 6 isolates (MT 984, MT 961, MT 1027, PP-42, AI $\mathrm{Al}_{130 \mathrm{~B}}$, NF-21.3) was stimulated by most (at least 27/34) supernatants, but these were not always the same ones and the stimulating supernatants were not related by origin of the producing isolates. Growth of the other 4 isolates (MT 1007, MT 975, MT 973 and TO.11.1) was stimulated by less than 20/34 supernatants. Among these, 2 isolates (MT 973, $\mathrm{AI}_{127 \mathrm{~B}}$ ) were stimulated by several supernatants but not by their own although their supernatants stimulated some other isolates. All isolates showed growth stimulation by supernatants from at least some other isolates grown under ironrestricted conditions except for one isolate (MT 1007), which was stimulated only by its own normal supernatant. Thus, although all supernatants did not stimu- 
Table 2. Aeromonas salmonicida. Cross-feeding assays of isolates. Fet: supernatant produced in iron normal medium. Fe--: supernatant produced in iron-restricted medium (10 $\mu \mathrm{M}$ EDDA) $+1-$ : positive/negative growth stimulation of isolates cultured with $>$ MIC EDDA

\begin{tabular}{|c|c|c|c|c|c|c|c|c|c|c|c|c|c|c|c|c|c|}
\hline \multirow{3}{*}{$\begin{array}{l}\text { Strain culture } \\
\text { MT984 }\end{array}$} & \multicolumn{16}{|c|}{ Strain supernatant } & \multirow[b]{2}{*}{$\begin{array}{l}\mathrm{MT} 1038 \\
\mathrm{Fe}+\mathrm{Fe}-\end{array}$} \\
\hline & \multicolumn{2}{|c|}{$\begin{array}{l}\text { MT984 } \\
\mathrm{Fe}+\mathrm{Fe}-\end{array}$} & \multicolumn{2}{|c|}{$\begin{array}{l}\text { MT1001 } \\
\text { Fe+ Fe- }\end{array}$} & \multicolumn{2}{|c|}{$\begin{array}{l}\mathrm{MT} 1007 \\
\mathrm{Fe}+\mathrm{Fe}-\end{array}$} & \multicolumn{2}{|c|}{$\begin{array}{l}\mathrm{MT} 975 \\
\mathrm{Fe}+\mathrm{Fe}-\end{array}$} & \multicolumn{2}{|c|}{$\begin{array}{l}\mathrm{MT} 1025 \\
\mathrm{Fe}+\mathrm{Fe}-\end{array}$} & \multicolumn{2}{|c|}{$\begin{array}{l}\text { MT973 } \\
\mathrm{Fe}+\mathrm{Fe}-\end{array}$} & \multicolumn{3}{|c|}{$\begin{array}{l}\mathrm{MT} 961 \\
\mathrm{Fe}+\mathrm{Fe}-\end{array}$} & $\begin{array}{l}\mathrm{MT} 1027 \\
\mathrm{Fe}+\mathrm{Fe}-\end{array}$ & \\
\hline & + & + & + & + & + & & + & + & + & - & + & + & & + & + & + & + \\
\hline MT1001 & + & + & + & + & + & & + & + & + & + & + & + & & + & + & + & + \\
\hline MT1007 & - & - & - & - & + & & - & - & - & - & - & - & & - & - & - & - \\
\hline MT975 & + & + & + & + & + & & + & + & - & - & - & - & & - & - & - & - \\
\hline MT1025 & + & + & + & + & + & & + & + & + & + & + & + & & + & + & + & + \\
\hline MT973 & + & + & + & + & - & & - & - & - & - & - & - & & + & + & - & - \\
\hline MT961 & + & + & + & + & + & & + & + & + & + & + & + & & + & + & + & + \\
\hline MT1027 & + & + & + & + & + & & + & + & + & + & + & + & & + & + & + & + \\
\hline MT1038 & + & + & + & + & + & & + & + & + & + & + & + & & + & + & + & + \\
\hline TO.11.1 & - & - & - & - & - & & - & - & - & - & - & - & & - & - & - & + \\
\hline PP -42 & + & + & + & + & + & & - & + & + & + & + & + & & + & + & + & + \\
\hline $\mathrm{AI}_{130 \mathrm{~B}}$ & + & + & + & + & + & & + & + & + & + & + & + & & + & + & + & t \\
\hline SCO4.1 & + & + & + & + & + & & + & + & + & + & + & + & & + & + & + & + \\
\hline $\mathrm{AI}_{12 \% \mathrm{~B}}$ & + & + & + & + & + & & + & + & + & + & + & + & & + & + & + & + \\
\hline$N F-21.3$ & + & + & + & + & + & & + & + & + & + & + & + & & + & + & + & + \\
\hline NF-19.1 & + & + & + & + & + & & + & + & + & + & + & + & & + & + & + & + \\
\hline PP-91 & + & + & + & + & + & & + & + & + & + & + & + & & + & + & + & + \\
\hline \multirow[t]{2}{*}{$\begin{array}{l}\text { Total no. isolates with } \\
\text { stimulated growth }\end{array}$} & 15 & 15 & 15 & 15 & $15 \quad 14$ & & 13 & 14 & 13 & 12 & 13 & 13 & & $4 \quad 1$ & 14 & $13 \quad 12$ & 14 \\
\hline & \multicolumn{2}{|c|}{$\begin{array}{l}\text { TO } 0.11 .1 \\
\mathrm{Fe}+\mathrm{Fe}-\end{array}$} & \multicolumn{2}{|c|}{$\begin{array}{c}\mathrm{PP}-42 \\
\mathrm{Fe}+\mathrm{Fe}-\end{array}$} & \multicolumn{3}{|c|}{$\begin{array}{l}\mathrm{AI}_{130 \mathrm{~B}} \\
\mathrm{Fe}+\mathrm{Fe}-\end{array}$} & \multicolumn{2}{|c|}{$\begin{array}{l}\mathrm{SCO} 4.1 \\
\mathrm{Fe}+\mathrm{Fe}-\end{array}$} & \multicolumn{2}{|c|}{$\begin{array}{l}\mathrm{Al}_{127 \mathrm{~B}} \\
\mathrm{Fe}+\mathrm{Fe}-\end{array}$} & \multicolumn{4}{|c|}{$\begin{array}{l}\mathrm{NF}-21.3 \\
\mathrm{Fe}+\mathrm{Fe}-\end{array}$} & $\begin{array}{l}\mathrm{NF}-19.1 \\
\mathrm{Fe}+\mathrm{Fe}-\end{array}$ & $\begin{array}{l}\mathrm{PP}-91 \\
\mathrm{Fe}+\mathrm{Fe}-\end{array}$ \\
\hline МТ984 & - & + & + & + & + & + & & + & + & + & - & & + & + & & + & + \\
\hline MT1001 & + & + & + & + & + & + & & + & + & + & - & & + & + & & + & + \\
\hline MT 1007 & - & - & - & - & - & - & & - & - & - & - & & - & - & & - & - \\
\hline MT975 & - & - & - & - & - & - & & - & - & - & - & & - & - & & - & - \\
\hline MT1.025 & + & + & + & + & + & + & & + & + & + & - & & + & + & & + & + \\
\hline МТ973 & - & + & + & - & - & - & & - & - & - & - & & + & + & & + & + \\
\hline MT961 & - & + & + & + & + & - & & + & + & + & - & & + & + & & + & + \\
\hline MT1027 & + & + & + & + & + & -- & & + & + & + & - & & + & + & & + & + \\
\hline MT1038 & + & + & + & + & + & + & & + & + & + & + & & + & + & & + & + \\
\hline T0.11.1 & + & + & + & + & + & + & & + & + & + & - & & + & + & & + & + \\
\hline PP-42 & - & + & + & + & - & - & & + & + & + & - & & - & + & & + & + \\
\hline $\mathrm{AI}_{130 \mathrm{~B}}$ & - & + & + & + & - & + & & + & + & + & - & & + & + & & + & + \\
\hline $\mathrm{SCO} 4.1$ & + & + & + & + & + & + & & + & + & + & - & & + & + & & + & + \\
\hline $\mathrm{AI}_{127 \mathrm{~B}}$ & - & + & + & + & - & - & & - & + & - & - & & - & + & & - & + \\
\hline$N F-21.3$ & - & + & + & + & + & + & & + & + & + & - & & + & + & & + & + \\
\hline$N F-19.1$ & + & + & + & + & + & + & & + & + & + & - & & + & + & & + & + \\
\hline PP-91 & + & + & + & + & + & + & & + & + & + & - & & + & + & & + & + \\
\hline $\begin{array}{l}\text { Total no. isolates with } \\
\text { stimulated growth }\end{array}$ & 8 & 15 & 15 & 14 & 11 & 10 & & 13 & 14 & 13 & 1 & & 13 & 15 & & $14 \quad 15$ & $15 \quad 15$ \\
\hline
\end{tabular}

late growth of all isolates assayed, with only the exception of MT 1007, growth of all isolates was stimulated by supernatants from several other isolates obtained in iron or non-iron-restricted conditions.

No important changes in the number of stimulated isolates in the siderophore bioassay were found between non-iron-restricted and iron-restricted supernatants of any isolate though some slight increase in the number of heterologous isolates stimulated by iron-restricted supernatants (especially of TO.11.1) was observed (Table 2). The only exception to this was isolate $\mathrm{Al}_{127 \mathrm{~B}}$, whose supernatant obtained in non-iron- restricted conditions cross-fed 13 isolates while the iron-restricted supernatant only cross-fed one (Table 2).

None of the indicator mutant bacteria tested in crossfeeding assays were stimulated by the iron-restricted supernatant of Aeromonas salmonicida isolate TO.11.1

\section{IROMPs analysis}

Outer membrane proteins from all the isolates when grown with and without available iron were examined. Growth in iron-restricted conditions was associated 


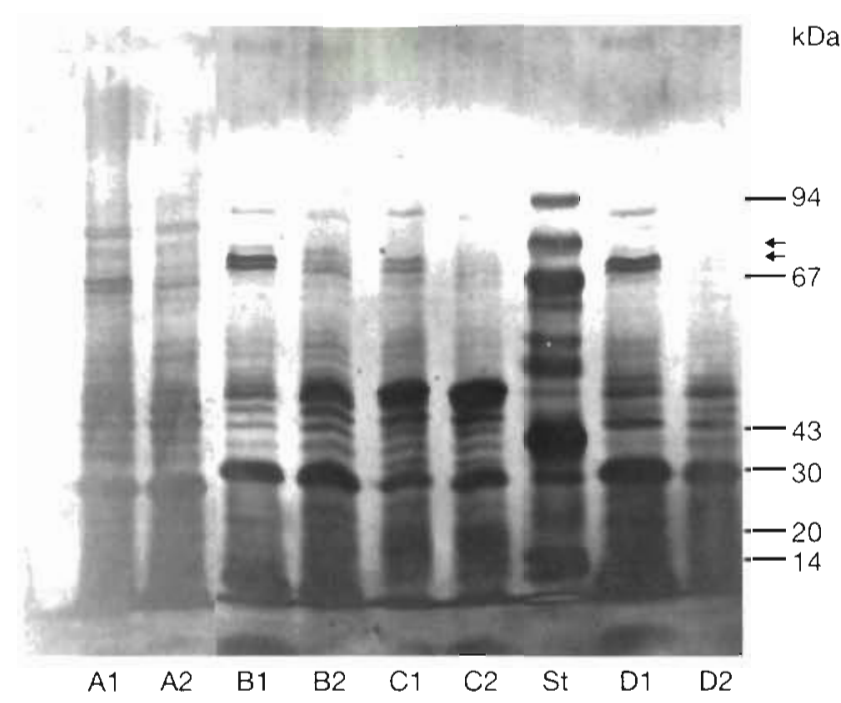

Fig. 1. Aeromonas salmonicida. Sodium dodecyl sulfatepolyacrylamide gel electrophoresis (SDS-PAGE) analysis of the outer membrane fraction isolated from cells grown in ironrestricted conditions (CM9+10 $\mathrm{MM}$ EDDA medium) in lanes 1 and non-iron-restricted conditions (CM9) in lanes 2. Proteins were stained with slver stain. A: $\mathrm{Al}_{130 \mathrm{~B}}$ B: NF-19.1; C: SCO4.1:

St: Pharmacia low molecular weight standard; D: PP-42

with an inducible increment in the amount of 2 outer membrane bands with molecular weights of 72 and $75 \mathrm{kDa}$. These bands were common to all 17 isolates Examples are shown in Fig. 1.

\section{DISCUSSION}

All the isolates examined in this study were able to grow in the presence of the high-affinity iron chelator EDDA, and siderophore production was detected using the universal chemical assay, CAS agar. This confirms previous reports (Hirst et al. 1991, Zywno et al. 1992) that typical strains of Aeromonas salmonicida possess a high-affinity siderophore iron-uptake mechanism. Previous work (Hirst et al. 1991), using 4 typical strains, reported that in cross-feeding assays supernatants of 3 strains stimulated growth of the homologous bacteria only, suggesting strain specificity in the siderophore produced. However, the remaining strain studied produced a culture supernatant with growthstimulating activity for the other typical as well as atypical strains of $A$. salmonicida (Hirst et al. 1991).

The present results using 17 typical isolates showed that the siderophore present in iron-restricted and noniron-restricted culture supernatants stimulated growth of both homologous and most heterologous isolates, indicating no siderophore strain specificity in Aeromonas salmonicida. As some isolates had a higher MIC for EDDA than others, the concentration of EDDA used in the bioassay plates was not constant and, as the concentration of siderophores in the test supernatants was variable, this may explain the variation with which certain supernatants stimulated the growth of some isolates and not others and may also be the explanation for the results reported by Hirst et al. (1991).

The positive results in cross-feeding assays using non-iron-restricted culture supernatants showed the production of siderophores after $48 \mathrm{~h}$ of growth, probably because after logarithmic growth iron may have become limiting, thus stimulating some siderophore production. However, in general, iron-restricted conditions enhanced siderophore production as detected by the Arnow assay for catechol siderophore in $12 / 17$ isolates. These results indicated that a catechol siderophore was produced and confirmed the results of Hirst et al. (1991), who found catechol siderophore in noniron-restricted culture supernatants using the Rioux et al. (1983) method. On the other hand, while the Atkin assay for hydroxamate siderophores was positive, the decrease in concentration in iron-restricted supernatants in nearly all isolates tested suggested that this compound could not be considered as a siderophore.

All 17 Aeromonas salmonicida isolates produced 2 major outer membrane proteins when grown in ironrestricted conditions. The molecular weights were similar to those described by Chart \& Trust (1983), Aoki \& Holland (1985) and Hirst \& Ellis (1994). Collighan et al. (1998) have demonstrated from gene sequencing data that the IROMPs have homology with the siderophore receptors of Escherichia coli and Vibrio anguillarum. Thus, siderophore receptor IROMPs appear to be common to all typical A. salmonicida strains.

The exart nature of Aeromonas salmonicida siderophore is still controversial. Previous studies (Hirst et al. 1991) found that the siderophore produced by typical strains behaves as a catechol-phenolate in several colorimetric assays, and culture supernatants of $A$. hydrophila 1108 and Vibrio anguillarum 2286 (775 pJM1) containing amonobactin and anguibactin were unable to promote the growth of typical $A$. salmonicida strains. However, culture supernatants of bacteria containing enterobactin (A. hydrophila $\mathrm{B}_{32}$ and 80-A1; Enterobacter cloacae, NCTC 11580 and Escherichia coli, NCTC 9001 and NCTC 50147) promoted growth of A. salmonicida to a small extent (Hirst et al. 1991). This suggests differences in the chemical nature of the inducible catechol siderophore of $A$. salmonicida and enterobactin. It has also been reported (Zywno et al. 1992) that 9/10 strains of A. salmonicida genospecies produced amonobactin, a phenolate siderophore containing DHBA, and only one produced no siderophore. 
Our results using the Arnow assay confirmed production of a catechol siderophore, but cross-feeding assays showed that the siderophore of Aeromonas salmonicida isolate TO.11.1 failed to induce the growth of mutant bacteria requiring exogenous catechol siderophores including anguibactin, enterobactin, DHBA, or the hydroxamate siderophore, aerobactin, indicating that $A$. salmonicida does not produce these siderophores. Further studies are necessary to confirm production of amonobactin by $A$. salmonicida.

From the results we conclude that a catechol siderophore is widely produced among Aeromonas salmonicida isolates, that typical strains possess a common siderophore receptor induced by iron-restricted culture conditions and that siderophore strain specificity is not apparent. Thus, as with many other characteristics, the siderophores and their receptors appear to be homogeneous in A. salmonicida subsp. salmonicida.

Acknowledgements. A.I.G.F., A.F.F. and M.J.P. thank the Conselleria de Educación e Ordenación Universitaria, Xunta de Galicia (Spain) for research fellowships. This work was supported by grants from the Comision Interministerial de Ciencia y Tecnología (AGF 94-0373), Madrid and the Consellería de Educación e Ordenación Universitaria, Xunta de Galicia (XUGA 3015B94), Spain.

\section{LITERATURE CITED}

Aoki T, Holland, BI (1985) The outer membrane proteins of the fish pathogens Aeromonas hydrophila, Aeromonas salmonicida and Edwarsiella tarda. FEMS Microbiol Lett 27:299-305

Arnow LE (1937) Colorimetric determination of the components of 3,4-dihydroxyphenylalanine-tyrosine mixtures. J Biol Chem 118:531-537

Atkin CL, Neiland JB, Phaff HJ (1970) Rhodotorulic acid from species of Leucosporidium, Rhodosporidium, Rhodotorula, Sporidiobolus and Sporobolomyces, and a new alaninecontaining ferrichrome from Cryptococcus meliviosum. J Bacteriol 103:722-733

Aznar R, Amaro C. Alcaide E, Lemos ML (1989) Siderophore production by environmental strains of Salmonella species. FEMS Microbiol Lett 57:7-12

Chart H, Trust TJ (1983) Acquisition of iron by Aeromonas salmonicida. J Bacteriol 156:758-764

Editorial responsibility: David Bruno,

Aberdeen, Scotland, UK
Collighan RJ, Bennet AJ, Coleman G (1998) Cloning, mapping and identification of the Aeromonas salmonicida fst $A$, fepA, and irpA genes, encoding the 86, 82 and $74 \mathrm{kDa}$ iron regulated outer membrane proteins respectively. Fish Pathol (in press)

Crosa JH, Potter SA, Walter MA (1983) Iron uptake-deficient mutants of Vibrio anguillarum 775 generated by insertional inactivation of the virulence plasmid pJM1. In: Schessinger D (ed) Microbiology. American Society for Microbiology, Washington DC, p 334-358

Filip C, Fletcher G, Wulf JL, Earthart CF (1973) Solubilisation of the cytoplasmic membrane of Escherichia colj by the ionic detergent sodium lauryl sarcosinate. J Bacteriol 115 : $717-722$

Hirst ID, Ellis AE (1994) Iron regulated outer membrane proteins of Aeromonas salmonicida are important protective antigens in Atlantic salmon against furunculosis. Fish Shellfish Immunol 4:29-45

Hirst ID, Hastings TS, Ellis AE (1991) Siderophore production by Aeromonas salmonicida. J Gen Microbiol 137: 1185-1192

Laemmli UK (1970) Cleavage of structural proteins during assembly of the head of bacteriophage T4. Nature 227 : $680-685$

Morrisey JM (1981) Silver stain for proteins in polyacrylamide gels: a modified procedure with enhanced uniform sensitivity. Anal Biochem 117:307-310

Munro ALS, Hastings TS (1993) Furunculosis. In: Inglis V, Roberts RJ, Bromage NR (eds) Bacterial diseases of fish Blackwell, Oxford, p 122-142

Neelam B, Robinson RA, Price NC, Stevens L (1993) The effect of iron limitation on the growth of Aeromonas salmonicida. Microbios 74:59-67

Pollack JR, Amos BN, Neilands JB (1970) Iron transport in Salmonella typhimurium: mutants blocked in the biosynthesis of enterobactin. J Bacteriol 104:635-639

Rioux C, Jordan DC, Rattray JBM (1983) Colorimetric determination of catechol siderophores in microbial cultures. Anal Biochem 133:163-169

Rogers HJ (1973) Iron-binding catechois and virulence in Escherichia coli. Infect Immun 7:445-456

Schwyn B, Neilands JB (1.987) Universal chemical assay for the detection and determination of siderophores. Anal Biochem 160:47-56

Williams PH (1979) Novel iron uptake system specified by ColV plasmids: an important component in the virulence of invasive strains of Escherichia coli. Infect Immun 26 : 925-932

Zywno SR, Arceneaux JEL, Alwetgg M. Byers BR (1992) Siderophore production and DNA hybridization groups of Aeromonas spp. J Clin Microbiol 30:619-622

Submitted: October 3, 1997; Accepted: March 26, 1998

Proofs received from author(s): May 26, 1998 